\title{
Influência de Meios Reacionais na Hidrólise de PET Pós-Consumo
}

\author{
Sandro D. Mancini \\ Departamento de Engenharia Química, UFC
}

\section{Maria Zanin \\ Núcleo de Reciclagem de Resíduos, DEMa, UFSCar}

Resumo: A despolimerização de poli (tereftalato de etileno) - PET - em água pura e em soluções aquosas $7,5 \mathrm{M}$ de ácido acético, ácido sulfúrico, acetato de sódio e hidróxido de sódio foi testada a $100^{\circ} \mathrm{C}$ e pressão atmosférica, com o objetivo de obter ácido tereftálico. Foram ainda quantificadas diferenças relativas à influência do tamanho de partícula na velocidade da reação. Água pura e soluções de ácido acético e acetato de sódio praticamente não degradaram o PET em cinco dias de reação, enquanto a solução de ácido sulfúrico permitiu $80 \%$ de despolimerização no período. A reação com solução de hidróxido de sódio foi considerada a melhor, pois despolimerizou 95\% do PET de granulometria maior (entre $2 \mathrm{~mm}$ e $1,199 \mathrm{~mm}$ ) em 7 horas e 98\% do PET de granulometria menor (inferior a 1,19mm) em 5 horas. Desta última reação o ácido tereftálico foi obtido, purificado e submetido a ensaios de caracterização, cujos resultados foram semelhantes aos do ácido tereftálico petroquímico (pureza superior a 99\%).

Palavras-chave: Hidrólise de PET, hidróxido de sódio, ácido tereftálico, despolimerização, reciclagem química.

\section{Influence of Reaction Media In Post-Consumer PET Hydrolysis}

Abstract: The depolymerization of polyethylene terephthalate - PET in pure water and in 7,5M aqueous solutions of acetic acid, sulfuric acid, sodium acetate and sodium hydroxide was tested at $100^{\circ} \mathrm{C}$ and $1 \mathrm{~atm}$, in order to obtain terephthalic acid (TPA). The effect from the size of the particles on the reaction kinetics was studied quantitatively. Pure water and the solutions of acetic acid and sodium acetate practically did not degrade PET after five days of reaction, while the sulfuric acid solution allowed $80 \%$ of depolymerization during the same period. Sodium hydroxide was the best hydrolysis agent, resulting in $95 \%$ depolymerization of the the larger particle size PET (between $2 \mathrm{~mm}$ and $1,19 \mathrm{~mm}$ ) in 7 hours and $98 \%$ of the smaller particle size PET (less than 1,19mm) in 5 hours. Terephthalic acid was obtained, purified and characterized, and the results were similar to those of petrochemical TPA (purity higher than 99\%).

Keywords: PET hydrolysis, sodium hydroxide, terephthalic acid, depolymerization, chemical recycling.

\section{Introdução}

A hidrólise de poli (tereftalato de etileno) vem sendo estudada desde o final dos anos $50 \mathrm{em}$ virtude de sua importância enquanto processo degradativo ${ }^{[1,2]}$. Buxbaum estimou que, entre 100 e $120^{\circ} \mathrm{C}$, a hidrólise de PET ocorre 10.000 vezes mais rapidamente que a degradação térmica e numa velocidade 5.000 vezes superior à oxidação do polímero $^{[3]}$. Esta vulnerabilidade do polímero em relação ao ataque hidrolítico faz com que a secagem do mesmo seja praticamente obrigatória anteriormente ao processamento, o que se aplica inclusive à reciclagem convencional do plástico.

Autor para correspondência: Maria Zanin, Núcleo de Reciclagem de Resíduos, Departamento de Engenharia de Materiais, UFSCar, Caixa Postal 676, CEP: 13565-905, São Carlos, SP. E-mail:dmza@power.ufscar.br 
A utilização da hidrólise como uma maneira de despolimerizar o poliéster está normalmente associada a sistemas pressurizados que permitam temperaturas superiores às da ebulição da água. Já sistemas desenvolvidos à temperaturas e pressões baixas, normalmente empregam concentrações relativamente elevadas de reagentes que alterem o $\mathrm{pH}$ do meio, fornecendo íons à reação ${ }^{[4]}$. No caso da hidrólise em meio ácido, assim como em meio neutro, o início da reação ocorre pela desestabilização da carbonila do grupo éster por meio do íon hidrogênio $\left(\mathrm{H}^{+}\right)$. Em meio alcalino, a ausência de íons hidrogênio para desestabilizar a carbonila é compensada pela presença de um reagente mais nucleófilo, normalmente um hidróxido $\left(\mathrm{OH}^{-}\right)$, ao invés da água. $\mathrm{O}$ cátion da base, mais forte que os poucos íons hidrogênio gerados pela ionização da água, completa a reação. Dessa forma, na hidrólise básica não é regra, como na hidrólise ácida e neutra, a formação de quantidades iguais de finais carboxílicos e hidroxílicos, podendo gerar, no limite da degradação, um sal do ácido tereftálico ${ }^{[3-6]}$.

A grande vantagem da utilização da hidrólise para reciclagem química, em detrimento de outros processos degradativos, é a possibilidade de obtenção de ácido tereftálico (TPA) com apenas uma reação. $\mathrm{O}$ ácido tereftálico produzido pode ser purificado ou esterificado com metanol para a produção de tereftalato de dimetila (DMT). A reação do TPA purificado com o etilenoglicol é a forma mais utilizada no Brasil para a síntese de PET, porém existem no país plantas que operam a polimerização do poliéster a partir da transesterificação do DMT com o glicol.

Dessa maneira, a hidrólise de PET pode contribuir no suprimento de monômeros de PET utilizando uma matéria-prima abundante e relativamente barata, os resíduos sólidos urbanos. O desenvolvimento de tecnologia nacional neste sentido é interessante, na medida em que a falta de quantidades suficientes faz com que o Brasil necessite importar fontes p-ftálicas (TPA e DMT), o que representou um ônus entre 1995 e 1999 da ordem de U\$ 130 milhões/ano ${ }^{[7,8]}$.

Este trabalho tem por objetivo quantificar a velocidade de degradação de PET em ambiente neutro, ácido e alcalino. Para tanto, foram mantidos constantes parâmetros reacionais importantes como a matéria-prima, granulometria, concentração dos agentes introduzidos, temperatura e pressão. Dessa maneira, contribui-se para uma comparação entre as reações, principalmente no tocante à exploração de cada uma enquanto técnica viável de reciclagem química. Embora a literatura apresente vários artigos sobre o assunto, a comparação entre resultados de outros autores não é possível, uma vez que praticamente todos os parâmetros experimentais são diferentes entre si ${ }^{[4,9-12]}$.

Outro objetivo do trabalho é a comparação de propriedades do monômero comercial, produzido em petroquímica pela oxidação do p-xileno, com o produzido pelo processo hidrolítico considerado mais produtivo e posteriormente submetido a um processo de purificação definido. Dessa maneira, é possível estudar alterações no processo de reciclagem química ou de purificação que levem à produção do monômero com grau de pureza que possibilite uma aplicação irrestrita do polímero.

\section{Experimental}

\section{Materiais}

A matéria-prima utilizada para o estudo foi o PET pós-consumo, selecionado, moído, lavado e seco dentro das unidades industriais da RECIPET e com tamanho de partícula inferior a $2 \mathrm{~mm}$. Com a finalidade de avaliar a influência da área superficial na reação, o material foi dividido em duas faixas granulométricas: a chamada grosseira com tamanho de partícula entre $2 \mathrm{~mm}$ e $1,19 \mathrm{~mm}$ (que representa cerca de $60 \%$ do material) e a fina, com flocos de tamanho inferiores a $1,19 \mathrm{~mm}$ (o restante $40 \%$ ).

$\mathrm{O}$ ácido acético (considerado um ácido fraco) e o ácido sulfúrico (ácido forte) foram escolhidos para compor os meios reacionais ácidos a terem sua reatividade com PET pós-consumo mensurada. $\mathrm{O}$ meio básico foi composto por soluções aquosas de hidróxido de sódio (considerada uma base forte) e pelo acetato de sódio. Este último trata-se de um sal com baixo poder de ionização, capaz de tornar o meio pouco alcalino. Reações somente com água também foram realizadas neste trabalho, de modo a possibilitar uma efetiva comparação com os outros meios reacionais.

\section{Hidrólise}

A relação entre a quantidade de água e a de polímero foi escolhida com base no estudo de Campanelli, Kamal e Cooper, que otimizaram a hidrólise neutra de PET fundido (temperaturas superiores a $235^{\circ} \mathrm{C}$ ). Segundo os autores, somente quan- 
tidades de água superiores a 5,1g de água/g de polímero foram capazes de despolimerizar todo o PET adicionado $^{[10]}$. A concentração molar do agente acrescentado para dar ao meio reacional um caráter ácido ou básico foi definida a partir de um estudo de Yoshioka, Sato e Okuwaki. De acordo com os resultados destes autores, somente concentrações superiores a $7 \mathrm{M}$ de ácido sulfúrico foram capazes de despolimerizar todo o PET adicionado em 5 horas de reação a $150^{\circ} \mathrm{C}$ num ambiente pressurizado ${ }^{[9]}$. Por esta razão, foi escolhida uma concentração levemente superior, $7,5 \mathrm{M}$, respeitando uma relação água/polímero maior ou igual a $5,1 \mathrm{~g} / \mathrm{g}$ e um volume total de líquido de $25 \mathrm{~mL}$, a quantidade mínima que permitiu boas condições experimentais.

A Tabela 1 apresenta as relações molares utilizadas para cada reação, concentrações em massa do soluto (ácido acético, ácido sulfúrico, acetato de sódio e hidróxido de sódio) e pH das soluções.

As reações foram realizadas em um balão de vidro acoplado a um condensador de refluxo. O balão foi imerso num banho de óleo mantido a aproximadamente $110^{\circ} \mathrm{C}$, o que permitiu que o líquido no interior do mesmo ficasse em temperatura aproximadamente constante a $100^{\circ} \mathrm{C}$. Essa temperatura foi escolhida como limite pois desejava-se realizar reações somente com água. Após determinado tempo, a reação, realizada com agitação magnética, foi interrompida e por meio de filtração se separou a fração líquida da sólida. Posteriormente, a fração sólida foi submetida a lavagem (com $250 \mathrm{~mL}$ de água destilada) e secagem (12 horas a temperatura ambiente e 5 horas a $75^{\circ} \mathrm{C}$ ).

No limite das despolimerizações de PET com ácido acético, sulfúrico, água pura e acetato de sódio, forma-se o ácido tereftálico, que fica na fase sólida, e o etilenoglicol, que vai para a fase líquida. Dessa forma, a extensão da reação foi medida a partir da quantificação do percentual de TPA formado na reação. Para tanto, uma amostragem de massa conhecida da fração sólida seca foi depositada num tubo de ensaio e neste foram colocados $15 \mathrm{~mL}$ de solução $5 \mathrm{M}$ de hidróxido de amônio. Após 10 minutos de reação com agitação magnética, a fração sólida (PET não completamente reagido) foi separada da líquida (contendo o sal de amônia, solúvel), submetida à secagem e posteriormente à pesagem ${ }^{[9]}$.

No caso da reação com solução de hidróxido de sódio, o limite da despolimerização forma, além do glicol, um sal de sódio do TPA (tereftalato dissódico), solúvel em água. Após a separação da fase sólida da solução reagente, a lavagem realizada foi suficiente para solubilizar o sal. Após a secagem da fração sólida, esta foi pesada e seu resultado comparado com a massa de polímero posta para reagir.

\section{Caracterização do TPA Obtido}

$\mathrm{O}$ meio reacional que propiciou a maior reatividade foi a solução de hidróxido de sódio, de forma que o TPA advindo de reciclagem química foi obtido a partir da acidificação da solução contendo o tereftalato dissódico. Esta acidificação foi realizada com ácido sulfúrico até se atingir uma solução com $\mathrm{pH}=0$, sendo formado o sulfato de sódio (solúvel em água) e o ácido tereftálico, que precipitou. Este foi separado por filtração e posteriormente submetido a lavagem, secagem e moagem. O produto que passou pela peneira de $0,30 \mathrm{~mm}$ foi considerado o TPA purificado proveniente de reciclagem química e foi caracterizado, assim como o TPA comercial, produzido petroquimicamente pela Rhodiaco, por meio de análise elementar e espectroscopia na região do infravermelho.

A análise elementar foi realizada no equipamento Fisons Instruments EA 1108 CHNS-O, por meio

Tabela 1. Valores das relações molares, concentrações em massa do soluto e pH das soluções utilizadas para as despolimerizações de PET pósconsumo

\begin{tabular}{lccc}
\hline \multicolumn{1}{c}{ Solução Aquosa de Soluto } & $\begin{array}{c}\text { Relação Molar } \\
\text { PET:Soluto:Água }\end{array}$ & \% em Massa de Soluto & pH \\
\hline Ácido Sulfúrico & $1: 12,26: 54,46$ & 55 & 0,6 \\
Ácido Acético & $1: 12,26: 56,28$ & 43 & 2,0 \\
Somente Água & $1: 0: 90,85$ & - & 7,3 \\
Acetato de Sódio & $1: 12,26: 90,85$ & 38 & 9,3 \\
Hidróxido de Sódio & $1: 12,26: 90,85$ & 23 & 13,5 \\
\hline
\end{tabular}


de aquecimento de amostra e o contato da mesma com agentes redutores e oxidantes. Da amostra orgânica original, obtém-se dióxido de carbono, gás nitrogênio, água e dióxido de enxofre, identificados e quantificados por um cromatógrafo gasoso. Um programa do equipamento calcula, com base nesses resultados, os percentuais de carbono, hidrogênio, nitrogênio, enxofre e, por diferença, oxigênio presentes na amostra ensaiada. A espectroscopia na região do infravermelho por transmissão foi realizada, após a preparação das amostras na forma de pastilhas com brometo de potássio, no equipamento Spectrum 1000 Perkin Elmer.

\section{Resultados e Discussão}

A Figura 1 apresenta os resultados das reações com PET nas duas granulometrias empregadas (grosso e fino) com água a $100^{\circ} \mathrm{C}$. Observa-se pela figura as baixas produtividade e reprodutibilidade da reação, caracterizadas pelos pequenos índices de conversão e pelos desvios-padrão relativamente altos. Nota-se ainda que a granulometria fina apresentou uma produtividade sempre superior à grosseira, o que era de se esperar dado a maior área superficial da primeira e pelo fato da reação ocorrer com o polímero no estado sólido. A figura revela que a reação hidrolítica a $100^{\circ} \mathrm{C}$ (cerca de $25^{\circ} \mathrm{C}$ acima da temperatura de transição vítrea do polímero) não chega a provocar nem 3\% de despolimerização após 5 dias de reação.

Nas Figuras 2 e 3 são apresentados os resultados das reações com soluções aquosas de ácido acético e

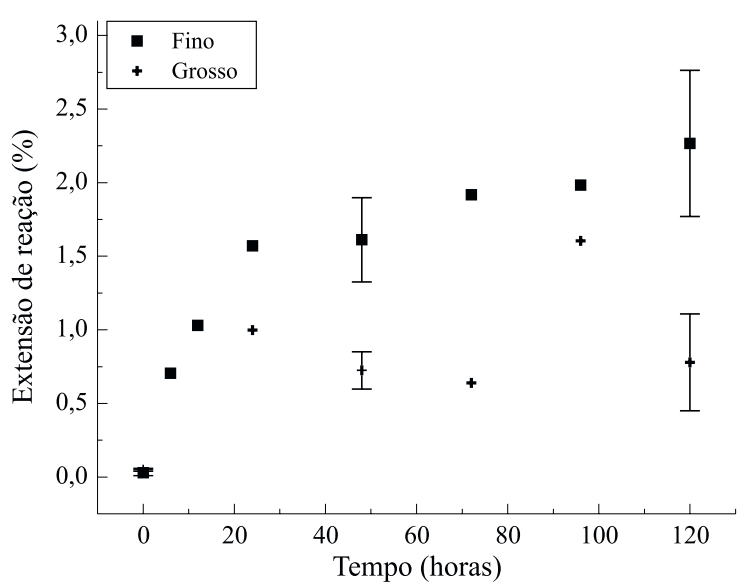

Figura 1. Resultados de extensão de reação em função do tempo de hidrólise de PET fino $(\square)$ e grosso $(+)$ submetidos à hidrólise com água a $100^{\circ} \mathrm{C}$ e pressão atmosférica acetato de sódio, respectivamente, também realizadas a $100^{\circ} \mathrm{C}$ e pressão atmosférica. Observa-se em ambas as figuras que o índice de despolimerização não passa de $3 \%$ e que não há tendência de crescimento da produtividade reacional em relação ao tempo e à diminuição do tamanho de partícula. Novamente, nota-se desvios-padrão relativamente altos, prejudicando ainda mais o estudo dos resultados.

Comparando-se os resultados das Figuras 2 e 3 com os da Figura 1, conclui-se que, nas condições adotadas, não devem ser utilizadas altas concentrações de acetato de sódio ou ácido acético, uma vez que a utilização não melhorou a produtividade reacional obtida com a água pura. Segundo Campanelli, Cooper e Kamal, íons gerados pela dissociação de catalisadores, como o acetato de sódio, diminuíram a repulsão eletrostática entre o polímero fundido e a água, aumentando a taxa

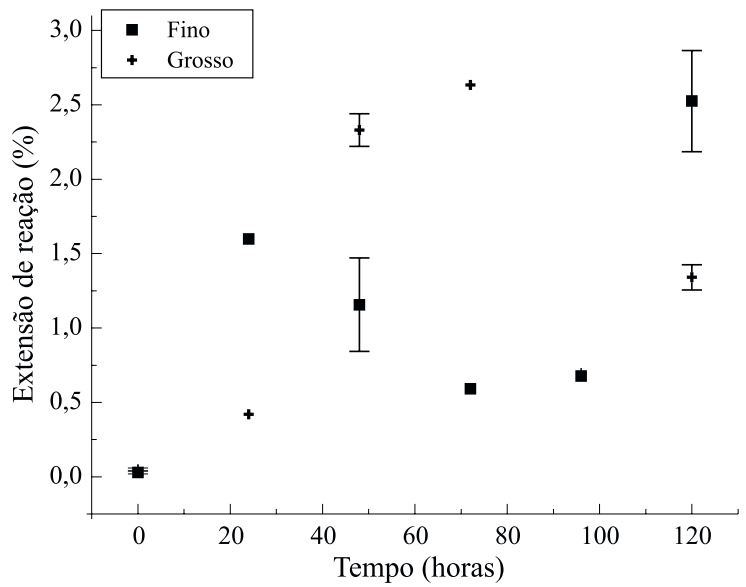

Figura 2. Resultados de extensão de reação em função do tempo de hidrólise de PET fino (ロ) e grosso (+) submetidos à hidrólise em solução aquosa de acetato de sódio $(7,5 \mathrm{M})$ a $100^{\circ} \mathrm{C}$ e $1 \mathrm{~atm}$

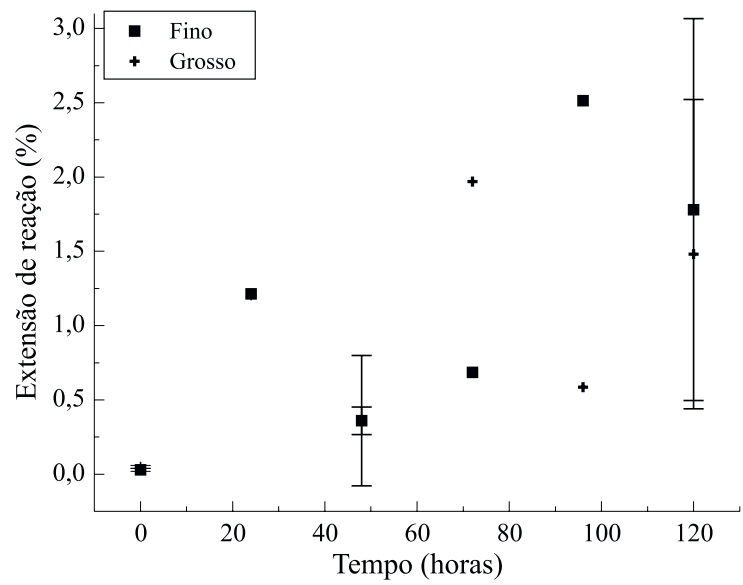

Figura 3. Resultados de extensão de reação em função do tempo de hidrólise de PET fino (ロ) e grosso $(+)$ submetidos à hidrólise em solução aquosa de ácido acético $(7,5 \mathrm{M})$ a $100^{\circ} \mathrm{C}$ e $1 \mathrm{~atm}$ 
de hidrólise ${ }^{[11]}$. De acordo com a Figura 2, este comportamento não se repetiu quando da reação do polímero no estado sólido.

A Figura 4 apresenta as curvas da extensão de reação em função do tempo para o PET (fino e grosso) hidrolisado em soluções aquosas de ácido sulfúrico $7,5 \mathrm{M}$ a $100^{\circ} \mathrm{C}$ e $1 \mathrm{~atm}$. A comparação com as Figuras 1, 2 e 3 revela uma grande reatividade do sistema hidrolítico em questão. Como todos os parâmetros reacionais foram mantidos constantes, esta reatividade apresentada na Figura 4 pode ser atribuída à ação do ácido sulfúrico, mais forte que o acético. Porém, a reatividade estacionou em $80 \%$ de conversão, não sendo possível alcançar índices superiores em tempos superiores. Assim como na reação com água (Figura 1), nas reações com soluções aquosas de ácido sulfúrico observou-se o caráter superficial da reação hidrolítica, caracterizada por uma maior reatividade da granulometria fina e evidenciada pelo deslocamento para esquerda de suas curvas em relação às curvas do material grosseiro.

Os resultados de extensão em função do tempo de reação para as amostras de PET fino e grosso reagidas em soluções aquosas de hidróxido de sódio $7,5 \mathrm{M}$ a $100^{\circ} \mathrm{C}$ e $1 \mathrm{~atm}$ são apresentados na Figura 5.

Embora a curva da Figura 5 apresente um patamar superior com baixa taxa de reação, este é atingido em níveis superiores aos observados na Figura 4. Enquanto para a hidrólise ácida o máximo de reatividade atingiu $80 \%$, no caso da reação com hidróxido de sódio este máximo foi alcançado em $98 \%$ para o fino e $95 \%$ para o grosseiro. Normalmente, a obtenção destes índices de conversão é con-

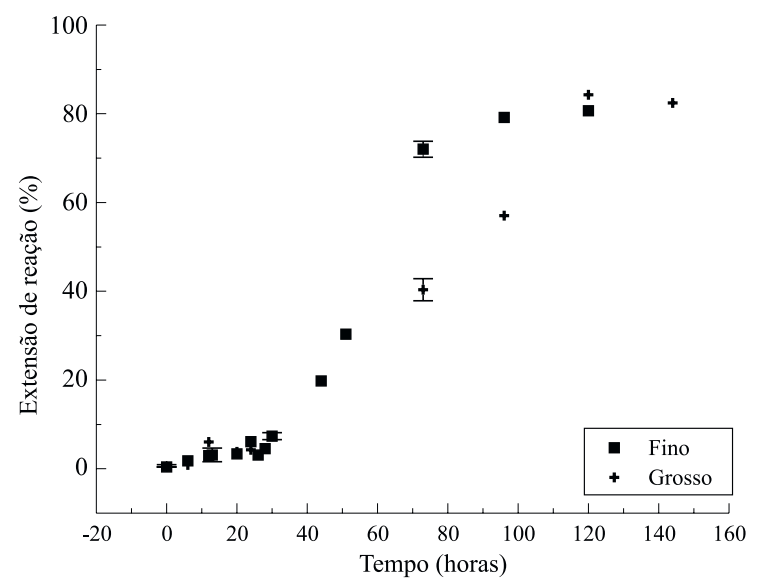

Figura 4. Resultados de extensão de reação em função do tempo de hidrólise de PET fino $(\boldsymbol{\square})$ e grosso $(+)$ submetidos à hidrólise em solução aquosa de ácido sulfúrico $(7,5 \mathrm{M})$ a $100^{\circ} \mathrm{C}$ e $1 \mathrm{~atm}$

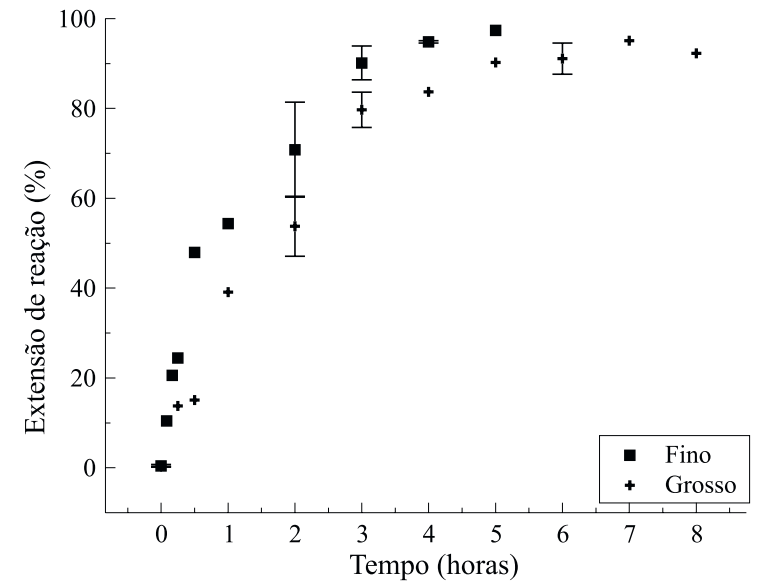

Figura 5. Resultados de extensão de reação em função do tempo de hidrólise de PET fino (ם) e grosso (+) submetidos à reação em solução aquosa de hidróxido de sódio $(7,5 \mathrm{M})$ a $100^{\circ} \mathrm{C}$ e 1 atm

siderada como reação completa, devido à dificuldade de acesso às poucas e pequenas partículas presentes, bem como a problemas experimentais como impregnação de material nas paredes do reator, tornando algumas partículas inacessíveis ao reagente e computando desfavoravelmente na reatividade total. Porém, a maior diferença observada entre a Figura 5 com relação às anteriores se dá com relação ao tempo de reação. Para despolimerização praticamente completa foram necessárias 7 horas do material grosseiro em reação com a solução alcalina e 5 horas do material fino.

O comportamento da reação de PET em solução de ácido sulfúrico (Figura 4), que se apresenta com um patamar inferior (período de indução), uma região de alta reatividade e um patamar superior (estagnação), foi também observado por Yoshioka, Sato e Okuwaki. Com base em estudos de microscopia eletrônica de varredura, os autores relacionaram o ponto de inflexão da curva, a partir do qual a taxa de reação cresce consideravelmente, com um grande aumento na área superficial das partículas devido à ação do ácido sulfúrico ${ }^{[9]}$.

As reações em solução de hidróxido de sódio (Figura 5) são muito rápidas e não apresentam o período de indução, formando curvas de extensão em função do tempo já na região de crescimento acelerado. A ausência do patamar inferior se dá, provavelmente, devido à alta reatividade do hidróxido de sódio em comparação com a água, o que faz com que seu ataque inicial à superfície seja superior inclusive à hidrólise catalisada por um ácido muito forte, como o sulfúrico. 
Como a despolimerização de PET foi mais rápida com a solução aquosa de hidróxido de sódio, esta foi escolhida para a obtenção de TPA. O processo de formação de um sal de TPA e sua posterior acidificação, precipitação, filtração, lavagem, secagem e moagem é considerado uma purificação do ácido tereftálico, embora industrialmente seja preferida a sublimação fracionada do mesmo ${ }^{[13]}$.

A Figura 6 apresenta os espectros na região do infravermelho do PET utilizado nas despolimerizações, do ácido tereftálico proveniente de reciclagem química e do TPA comercial. Observa-se pela Figura 6 nítidas diferenças entre os espectros do PET e dos ácidos tereftálicos. Em contrapartida, os gráficos dos TPAs praticamente se superpõem, com espectros típicos de ácido carboxílicos. No caso dos monômeros, o espectro é definido pela larga banda entre 3400 e $2200 \mathrm{~cm}^{-1}$, atribuída ao final $-\mathrm{OH}$ ligado à carbonila, bem como o próprio pico da carbonila, que se localiza em $1680 \mathrm{~cm}^{-1}$ e não mais em $1715 \mathrm{~cm}^{-1}$ como no PET. Estas considerações e a comparação com espectros de TPA encontrados na literatura contribuem para a confirmação positiva dos espectros como sendo de ácido tereftálico, corroborando o processo de reciclagem química e de purificação adotados ${ }^{[14,15]}$.

A Tabela 2 apresenta os resultados de análise elementar do PET utilizado, do TPA obtido via despolimerização bem como do TPA comercial.

Como esperado, somente na amostra de TPA, obtida via reciclagem química houve o registro de enxofre $(0,08 \%)$, uma vez que o processo empregado para a obtenção do mesmo, após a despolimerização, envolve a utilização de ácido sulfúrico. Desta maneira, tais resultados sugerem que a acidificação

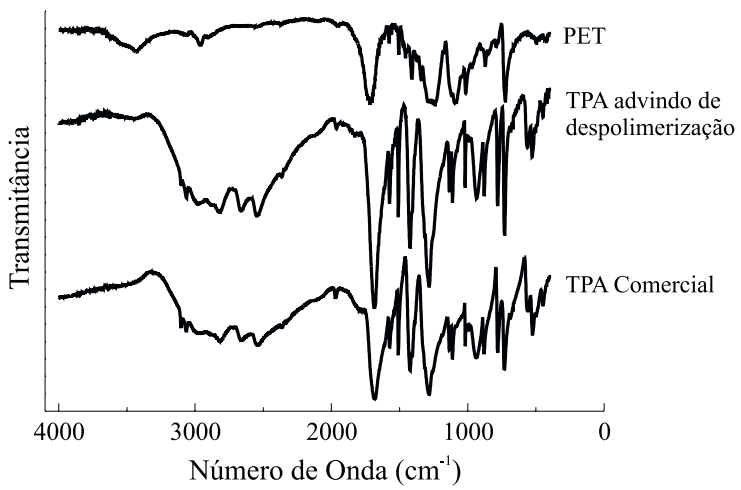

Figura 6. Espectros na região do infravermelho do PET pós-consumo utilizado para as reações, bem como do TPA obtido a partir da despolimerização com solução aquosa de hidróxido de sódio e do TPA comercial, fabricado petroquimicamente
Tabela 2. Resultados de análise elementar do TPA obtido via despolimerização de PET com solução aquosa de hidróxido de sódio, do PET utilizado nas reações, bem como do TPA comercial

\begin{tabular}{lcccc}
\hline TPA proveniente de & $\mathbf{\% C}$ & $\mathbf{\% H}$ & $\mathbf{\% S}$ & $\mathbf{\% O}$ \\
\hline PET utilizado & 63,31 & 4,50 & 0,00 & 32,19 \\
TPA obtido & 58,20 & 3,68 & 0,08 & 38,04 \\
TPA Comercial & 58,52 & 3,80 & 0,00 & 37,68 \\
\hline
\end{tabular}

e/ou a posterior lavagem do TPA empregadas devem ser otimizadas para anular o percentual verificado. Os resultados do percentual de carbono, hidrogênio e oxigênio do TPA obtido apontam para índices distantes dos de PET, mas próximos dos do monômero comercial, o que contribui na identificação positiva do material obtido como sendo ácido tereftálico. A pureza do TPA, produzido para o estudo, em relação ao comercial, calculada em base carbono, fornece $99,4 \%$. Segundo a literatura, o ácido tereftálico com pureza inferior a $99,5 \%$ fornece baixa produtividade na esterificação direta com o etilenoglicol, existindo registros de pureza superior a 99,9\% ${ }^{[13,16]}$. Assim sendo, o TPA produzido e purificado para o estudo poderia ter duas destinações: um novo processo de purificação ou a esterificação com metanol, o que daria origem ao DMT.

\section{Conclusões}

A reatividade de flocos provenientes de garrafas moídas de PET foi testada a $100^{\circ} \mathrm{C}$ e 1 atm em água e em soluções 7,5 M de ácido acético, ácido sulfúrico, acetato de sódio e hidróxido de sódio. As soluções de ácido acético e acetato de sódio apresentaram pouca reatividade, assim como as reações com água, não ultrapassando 3\% de despolimerização após cinco dias de reação. Já a reatividade da solução de ácido sulfúrico alcançou cerca de $80 \%$ de degradação no período. Porém, o melhor sistema de despolimerização foi a solução aquosa de hidróxido de sódio, que promoveu até $98 \%$ de degradação em cinco horas de reação. Os melhores resultados foram sempre obtidos com os flocos de granulometria fina (menor que $1,19 \mathrm{~mm}$ ) em relação à grosseira (entre $2 \mathrm{~mm}$ e $1,19 \mathrm{~mm}$ ).

O ácido tereftálico foi então precipitado a partir da acidificação da solução contendo tereftalato dissódico (produto da hidrólise alcalina), filtrado, lavado, seco e moído e submetido a ensaios de infravermelho e análise elementar, que permitiram concluir que se trata de 
um material semelhante ao produzido petroquimicamente e com pureza de $99,4 \%$.

\section{Agradecimentos}

Pelo suporte financeiro, os autores agradecem à CAPES (PICD-UFC) e à FAPESP (bolsa de iniciação científica-processo 99/04323-0- e Projeto de Auxílio à Pesquisa -00/06867-6-). Os autores agradecem ainda à Recipet, Rhodia, Jener de Oliveira, Antônio Carlos Rosalini, César Mariano de Carvalho, à professora Sati Manrich e ao professor Luís Antônio Pessan.

\section{Referências Bibliográficas}

1. Mcmahon, W.; Birdsall, H. A.; Johnson, G. R.; Camilli, C. T. J. - Chem. Eng. Data, v.4, n. 1, p. 57 (1959).

2. Ravens, D. A. S. e Ward, I. M. - Trans. Far. Soc., v. 57, 149 (1960).

3. Buxbaum, L. H. - Angew. Chem. Int. Ed., v. 7, n.3, p. 182 (1968).

4. Paszun, D. \& Spychaj, T. - Ind. Eng. Chem. Res., v. 36, p. 1373 (1997).

5. Allen, N. S.; Edge, M.; Mohammadian, M. \& Jones, K. - Polym. Deg. Stab., n. 43, p. 229 (1994).

6. Reich, L.; Stivala, S. S. - "Elements of Polymer Degradation”. Mcgraw Hill - Nova Iorque (1971).
7. Associação Brasileira da Indústria Química. Anuário da Indústria Química 2000. Ano 27, Abiquim, São Paulo (2001).

8. Mancini, S. D. - "Estudos de Hidrólise de PET PósConsumo no Estado Sólido Visando a Reciclagem Química". Tese de Doutorado, Universidade Federal de São Carlos (2001).

9. Yoshioka, T.; Sato, T. \& Okuwaki, A. - J. Appl. Polym. Sci.. V. 52. P.1353 (1994).

10. Campanelli, J. R.; Kamal, M. R. \& Cooper, D. G. - J. Appl. Polym. Sci. V.48, 443 (1993).

11. Campanelli, J. R.; Cooper, D. G.; Kamal, M. R. - J. Appl. Polym. Sci. V. 53, p. 985 (1994).

12. Ramsdem, J.; Philips, J. A. - J. Chem. Tech. Biotech., v. 67 , p. 131(1996).

13. Bryant, H. S.; Duval, C. A.; Mcmakin, L. E. \& Savoca, J. I. - Chem. Eng. Progr. V. 7, n.9, p. 69 (1971).

14. The Sadtler Handbook of infrared spectra. Sadtler Research Laboratories Inc. (1978).

15. Silverstein, R. M.; Bassler, C. G. \& Morril, T. C. - "Spectrometric identification of organic compounds". $3^{\text {a }}$ Edição. John Wiley \& Sons - Nova Iorque (1974).

16. Park, C. M. \& Micklewright, D. G. - Patente Americana n. 4053506, (1975). Disponível em <http:// www.delphion. Com>. Acesso em 7 jan. 2001.

Recebido: $18 / 10 / 01$

Aprovado: 13/02/02 